\title{
PLANAR ACS FED DUAL BAND ANTENNA WITH DGS FOR WIRELESS APPLICATIONS
}

\author{
Ansal K A ${ }^{1}$ and T Shanmuganantham ${ }^{2}$ \\ ${ }^{12}$ Department of Electronics Engineering, Pondicherry Central University, Puducherry
}

\begin{abstract}
A novel Asymmetric Coplanar Strip (ACS) fed antenna with Defected Ground Structure (DGS) suitable for dual application is presented. The Method of Moments (MoM) based mentor graphics IE3D electromagnetic solver has been used for this design. Dual band operation has been obtained by modifying the ground plane of the proposed design with spur-slots. It has been fabricated and tested with the overall size of $21 \times 15 \times 1.6 \mathrm{~mm}^{3}$. The measured results indicate that the proposed antenna yields <-10dB impedance bandwidth of $13.13 \%$ and $9.86 \%$ which meets the requirement of $3.5 \mathrm{GHz}$ and $5.5 \mathrm{GHz}$ Wireless Local Area Network (WLAN) and World Wide Interoperability Microwave Access (WiMAX) applications. The approximate lumped equivalent circuit extraction for the proposed DGS fed dual band antenna has been discussed in detail. Because of its stable radiation patterns with low cross polarization,miniature size, high average antenna gain of $2.5 \mathrm{dBi}$ and good electromagnetic characteristics, the proposed antenna is a promising candidate for dual mode wireless communication devices.
\end{abstract}

\section{KEYWORDS}

Asymmetric coplanar strip, Coplanar waveguide,Defected ground structure,Dual band antennas.

\section{INTRODUCTION}

The tremendous demand for wireless portable gadget of high data rate communication requires need of integration for different radio module in a limited space. As a result, recently researchers have been mainly focusing on a development of highly miniaturized and low profile antennas. The coplanar waveguide antennas are promising candidates because of their attractive features like lightweight, broad bandwidth, uniplanar structure and easy integration with monolithic microwave integrated circuit. The two main design constraints for the design and development of compact planar antennas are their miniaturization and multiband performance. In general antenna designers to achieve multiband operations by modifying the radiator by adopting two design strategies. The first approach is to create a several radiators which contribute different resonances is starting from the same feeder i.e., the branched radiators. The second approach is to elongate the physical length of the main radiator to obtain the multiple resonant modes. However, by creating several branched radiators from the single feeder may occupy a large space, hence it increases the resulting antenna physically larger than the desired volume. So in this article a new miniaturization strategy is employed

Several investigations have been carried out to study the miniaturization of CPW fed dual band antennas like Lai et al. [1] presented miniaturization of CPW fed antenna with reactive termination and truncated bilateral ground plane. Liu et al. [2] presented a triple-band coplanar waveguide-fed monopole antenna with multiple branch strips for wireless applications. Chow Yen [3] proposed a dual band CPW fed antenna with asymmetrical ground for bandwidth enhancement which consists of two ground plane that are 
unsymmetrical, by varying the length of the ground plane to achieve broad bandwidth. However, the entire antenna occupies large ground plane which is bulky in nature. Sujith et al.[4] reported an architecture of CPW fed uniplanar antenna for multiband wireless applications. Amandeep Singh et al. [5] proposed a novel coplanar waveguide fed wideband printed monopole antenna with defected ground for wireless application. Yuanfu Liu et al. [6] reported a tri-band CPW fed stepped monopole antenna with inverted L-strip for WiMAX/WLAN application. Deepu et al. [7, 8] demonstrated a compact asymmetrical coplanar strip fed uniplanar antenna formixed band mobile communication and WLAN has achieved more compact size by using single lateral ground strip instead of twin lateral ground strip in the CPW feed. Yuan et al. [9] presented a compact asymmetric coplanar fed monopole antenna employing inverted L branches for WiMAX and WLAN application. Yingsong $\mathrm{Li}$ et al. $[10,11]$ proposed different miniaturized asymmetric coplanar strip antennas for multiband and wideband application. Askarali et al. [12] presented an asymmetric strip fed dual band antenna for DCS/WLAN application. Bo Li et al. [13] reported a triple band slot antenna with U-shape stub fed by asymmetric coplanar strip for WLAN and WiMAX applications deploys an open-ended stub which acts as parasites near to the exciting strip, for tuning the antenna into their required band of operation. But here, we proposed an antenna with open-ended tuning slit for tuning the desired band. Different types of design for various user requirements have been reported in [14-18]. These designs have complex structures and difficult to integrate with WLAN systems. In this paper, a simple compact ACS fed dual band antenna with defected ground structure operating at $3.5 \mathrm{GHz}$ and $5.5 \mathrm{GHz}$ for WiMAX and WLAN applications are presented. This proposed design exhibit all the advantages of conventional CPW fed design along with more compactness.

The use of ground planes with discontinuities in the planar transmission lines is currently employed to improve the performance of different passive circuits, the enhancement of filter/antenna characteristics and applications to suppress harmonics in the antennas. On the other hand, a new proposal called defected ground structure [19] has been successfully used for miniaturization and tuning for antennas into their desired band of operation. The DGS is an etched lattices on the ground plane of planar transmission line (e.g., micro strip, coplanar and conductor backed coplanar waveguide etc.) which is periodic or non-periodic in configuration that disturbs the shield current distribution in the ground plane. As a result, there is a change in the characteristics of a transmission line such as line capacitance and inductance.

\section{ANTENNA GEOMETRY}

The geometry of proposed ACS-fed antenna with U-shaped ground plane for dual band operation is shown in Fig.1. The antenna presented here is printed on a substrate with relative permittivity of $\varepsilon_{\mathrm{r}}=4.4$ and height $\mathrm{h}=1.6 \mathrm{~mm}$. A slit of width $\mathrm{w}=0.5 \mathrm{~mm}$ introduced in the ground plane for tuning the antenna into the desired band of resonance. The dimensions of the lateral ground plane are optimized at $12 \times 10 \mathrm{~mm}^{2}$ by which the defect is realized. The gap width $\mathrm{g}=0.35 \mathrm{~mm}$ optimized to get good impedance matching

The design equations $[20,21]$ for the perfect matching of impedance are given below;

$$
Z_{o}=\frac{60 \pi}{\sqrt{\varepsilon_{e f f}}} \frac{K(k)}{K\left(k^{1}\right)}
$$

Where, from Fig.1 c 
International Journal of Antennas (JANT) Vol.2, No.1, January 2016

$$
\begin{aligned}
& k=a / b \\
& k^{1}=\sqrt{1-k^{2}}
\end{aligned}
$$

and $\frac{K(k)}{K\left(k^{1}\right)}$ is the elliptical integral of first kind which is given by;

$$
\begin{aligned}
& \frac{K(k)}{K\left(k^{1}\right)}= \begin{cases}\frac{\pi}{\ln \frac{2\left(1+\sqrt{\left.k^{1}\right)}\right.}{\left(1-\sqrt{k^{1}}\right)}} & 0 \leq k \leq \frac{1}{\sqrt{2}} \\
\frac{1}{\pi \ln \frac{2(1+\sqrt{k)}}{(1-\sqrt{k)}}} & \frac{1}{\sqrt{2}} \leq k \leq 1\end{cases} \\
& \varepsilon_{\text {eff }}=\frac{\varepsilon_{r}+1}{2}
\end{aligned}
$$

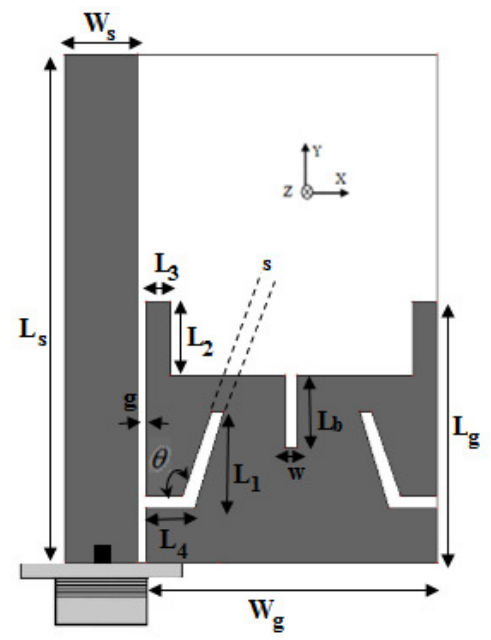

(a)

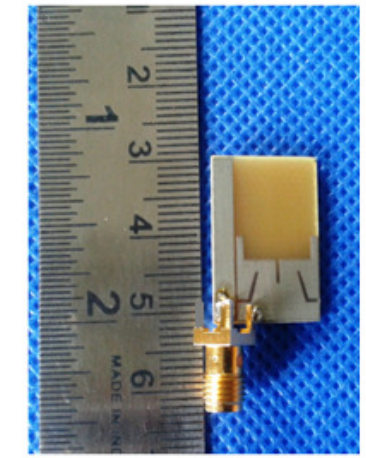

(b)

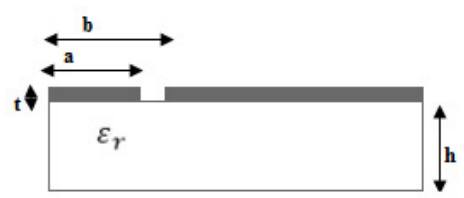

(c)

Fig.1 (a) Design layout of the proposed antenna (b) Photograph of the fabricated proposed antenna (c) Side view

Table 1.Proposed antenna specifications (in $\mathrm{mm}$ )

\begin{tabular}{|c|c|c|c|c|c|c|c|c|c|c|c|c|c|}
\hline Parameters & $\mathrm{L}_{\mathrm{S}}$ & $\mathrm{W}_{\mathrm{S}}$ & $\mathrm{L}_{\mathrm{g}}$ & $\mathrm{W}_{\mathrm{g}}$ & $\mathrm{L}_{\mathrm{b}}$ & $\mathrm{L}_{1}$ & $\mathrm{~L}_{2}$ & $\mathrm{~L}_{3}$ & $\mathrm{~L}_{4}$ & $\mathrm{w}$ & $\boldsymbol{\theta}$ & $\mathrm{s}$ & $\mathrm{g}$ \\
\hline
\end{tabular}


International Journal of Antennas (JANT) Vol.2, No.1, January 2016

\begin{tabular}{|l|l|l|l|l|l|l|l|l|l|l|l|l|l|}
\hline Values(mm) & 21 & 3 & 10 & 10 & 3 & 4 & 3 & 1 & 2 & 0.5 & $100^{0}$ & 0.5 & 0.35 \\
\hline
\end{tabular}

\section{RESULTS AND DISCUSSIONS}

The design and simulation and analysis of the proposed antenna have been performed using the commercially available Mentor GraphicsIE3D 15.10 electromagnetic solver software. The prototype of the presented antenna has been fabricated and measured as shown in figure 1, and it is experimentally validated using HP8510C vector network analyzer (VNA). The simulated and measured return loss characteristics of ACS fed proposed antenna is given in fig.2. It is observed that antenna resonates at $3.5 \mathrm{GHz}$ and $5.5 \mathrm{GHz}$ with good matching. It exhibits impedance bandwidth of $425 \mathrm{MHz}$ at $(3.25 \mathrm{GHz}-3.65 \mathrm{GHz})$ and $550 \mathrm{MHz}(5.3 \mathrm{GHz}-5.85 \mathrm{GHz})$ in the $3.5 \mathrm{GHz}$ and $5.5 \mathrm{GHz}$ bands respectively.

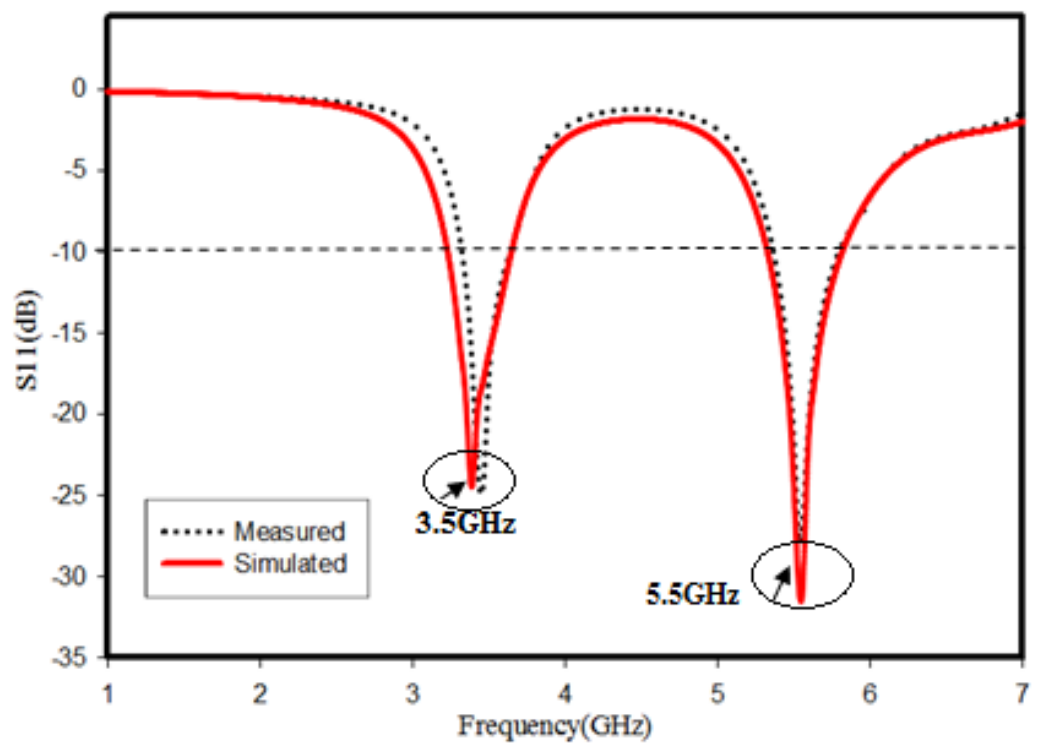

Figure. 2 Return Loss of the Proposed Antenna

In this article, an ACS fed dual band antenna for WiMAX /WLAN application is proposed. The bands are realized by etching a tapered spur slot symmetrically on the radiating ground plane. The parametric study of the proposed antenna with and without ground defect is shown in figure.3. We can see that with defects the resonance are obtained at $3.45 \mathrm{GHz}$ and $5.5 \mathrm{GHz}$ by including open-ended tuning slit. Consequently, the resonance brings down and obtains an average return loss about $-28 \mathrm{~dB}$. Here, we can notice that the tuning slit also plays an important role in bringing down the resonance to match with $50 \Omega$ characteristics impedance of the ACS feed line. 


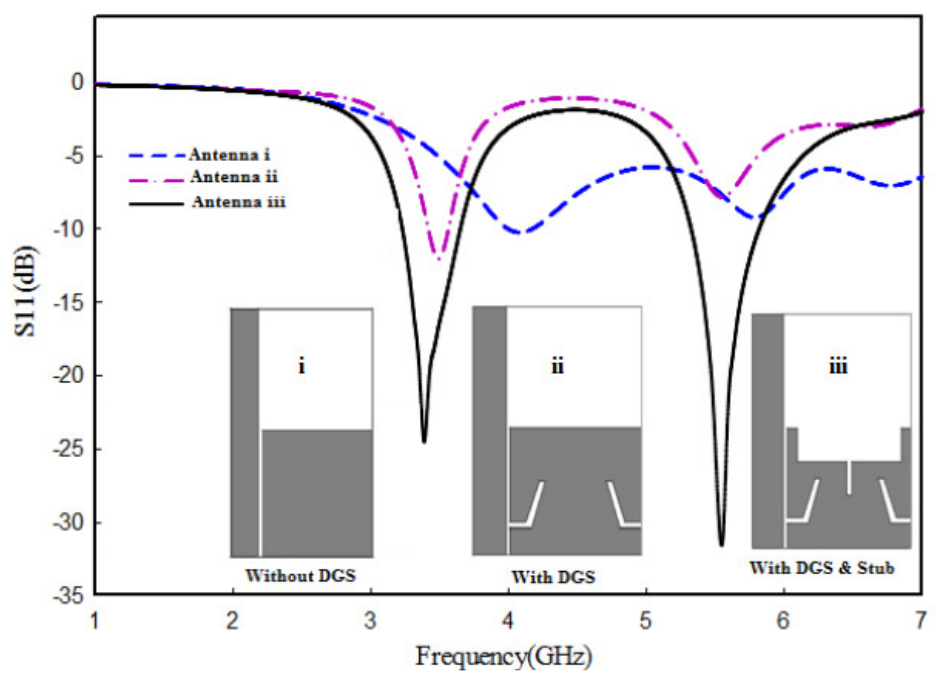

Figure.3 Comparison of return loss with andwithout DGS

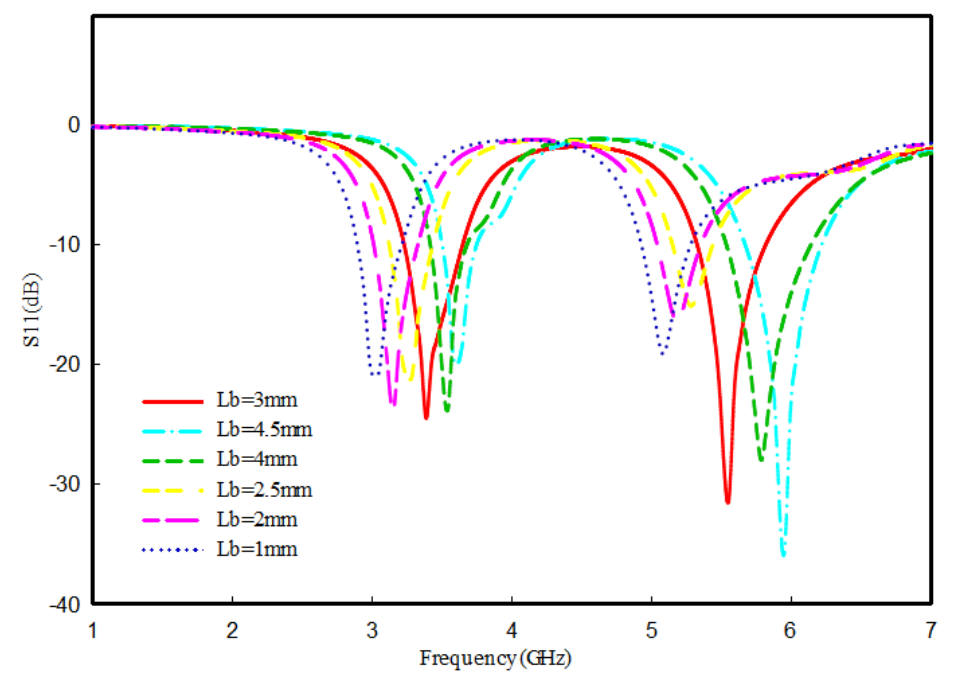

Figure.4Comparison of return loss characteristics by varying $L_{b}$

The length of the tuning slit is about the quarter of the guided wavelength calculated at lower band of resonance. The fig. 4 shows the comparison of return loss characteristics by varying open-ended tuning slit of length $\mathrm{L}_{\mathrm{b}}$ by keeping all other parameters are constant. Here, we can notice that $\mathrm{L}_{\mathrm{b}}$ has influence on both bands of resonance with $\mathrm{L}_{\mathrm{b}}=3 \mathrm{~mm}$ proposed antenna yields optimum resonance at $3.5 \mathrm{GHz}$ and $5.5 \mathrm{GHz}$. The parameter $\mathrm{L}_{\mathrm{b}}$ can be used for tuning the antenna at various adjacent frequencies.

The return loss characteristics of the antenna using different types of substrate materials are shown in fig.5.Here we can see that the substrate material is an important parameter for the 
antenna design. Thus, proposed antenna yields optimum result for FR4 epoxy substrate with permittivity of 4.4 and loss tangent of 0.02 . The different materials properties are shown in Table 2.

Table. 2 Material properties of the various dielectric materials

\begin{tabular}{|c|c|c|c|}
\hline Substrate & Permittivity & Loss tangent & $\begin{array}{c}\text { Thickness } \\
(\mathbf{m m})\end{array}$ \\
\hline FR4 & 4.4 & 0.02 & 1.6 \\
\hline RT5880 & 2.2 & 0.0015 & 1.6 \\
\hline RT5870 & 2.33 & 0.0012 & 1.6 \\
\hline RT6010 & 10.2 & 0.002 & 1.6 \\
\hline Bio Plastic & 15 & 0.002 & 1.6 \\
\hline
\end{tabular}

Fig.6 shows the simulation result of the reflection coefficientof the antenna for FR4 substrate thicknessesof $0.5 \mathrm{~mm}, 0.8 \mathrm{~mm}, 1 \mathrm{~mm}$ and $1.6 \mathrm{~mm}$. FromFig. 4, it is clearly observed that the best performanceof the proposed antenna hasbeen noticed byusing a thicknessof $1.6 \mathrm{~mm}$. Because, substrate's thickness will increases theradiated power and to improve the performance.

The Fig. 7 shows measured $\mathrm{E}$ and $\mathrm{H}$-plane $2 \mathrm{D}$ radiation patterns of the antenna at $3.5 \mathrm{GHz}$ and $5.5 \mathrm{GHz}$ respectively. The radiation patterns are omni-directional at lower and upper resonance in $\mathrm{H}-$ plane and in E-plane, radiation patterns are bidirectional. The cross polarization levels are minimum when compared to co-polarization levels for both $\mathrm{E}$ and $\mathrm{H}$ plane. The patterns are slightly asymmetric because of the asymmetry in antenna feeding configuration. The polarization of the antenna is also experimentally tested and determined and it is found that the antenna is linearly polarized along $\mathrm{X}$-axis for the dual-band of operation. 
International Journal of Antennas (JANT) Vol.2, No.1, January 2016

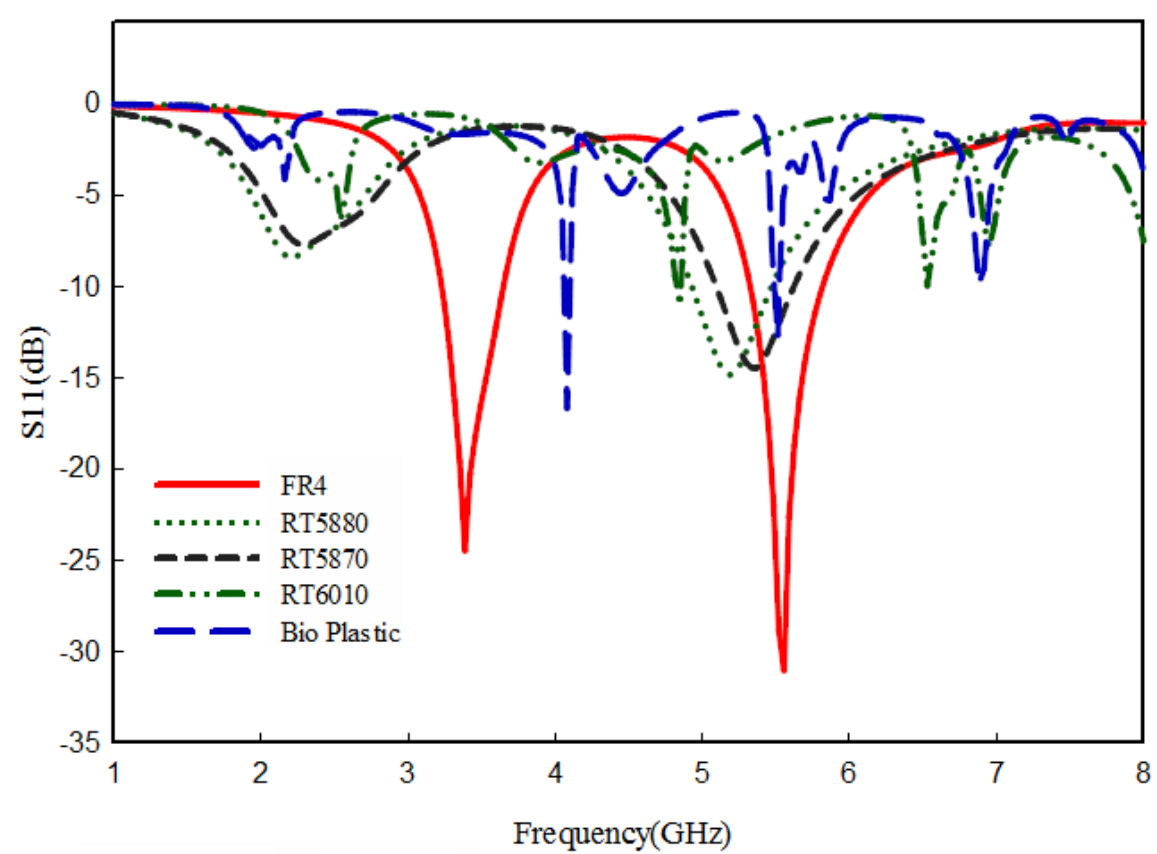

Figure.5 Comparison between reflection coefficient for different types of substrate

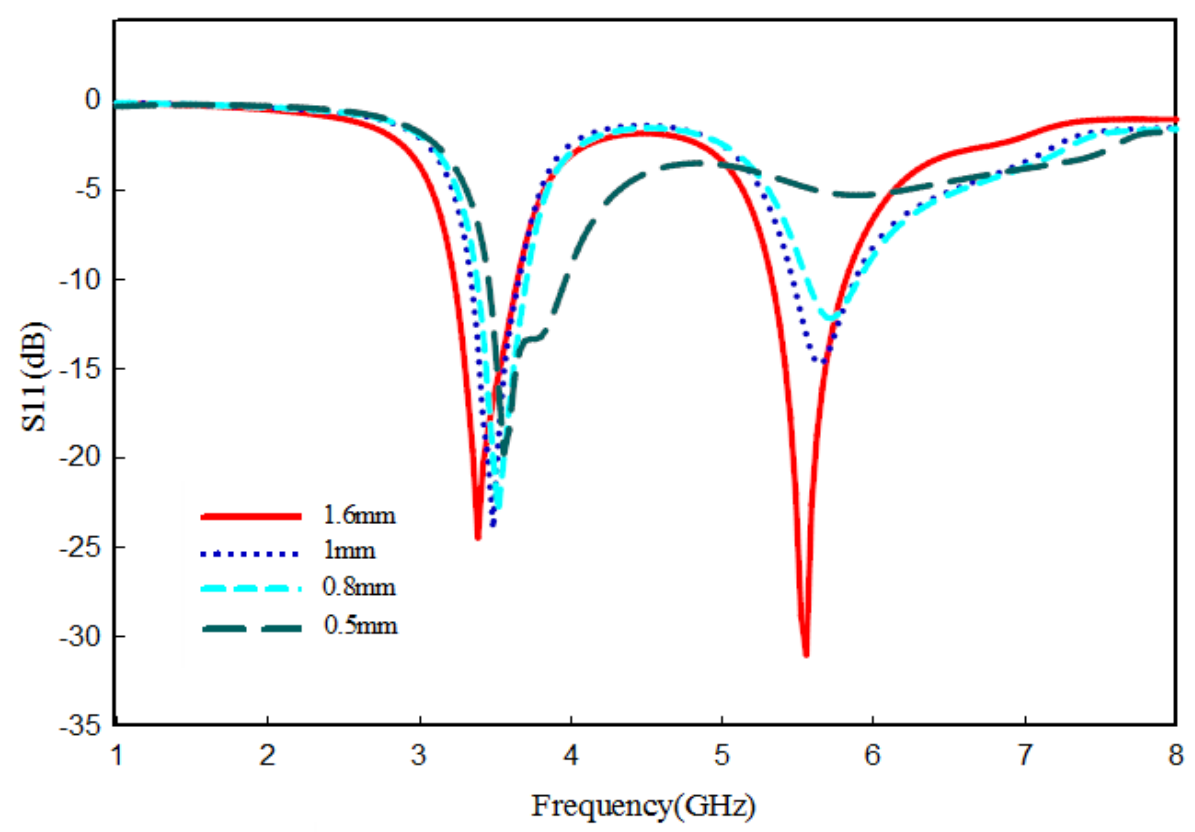

Figure.6 Reflection coefficient characteristics for different values of substrate thickness 

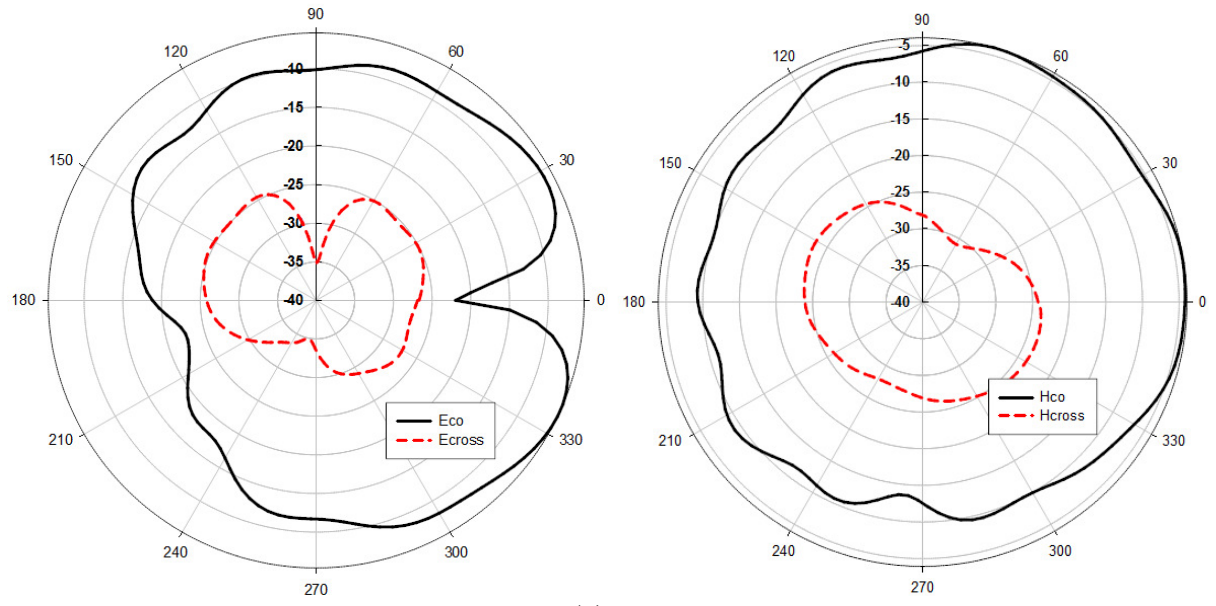

(a)
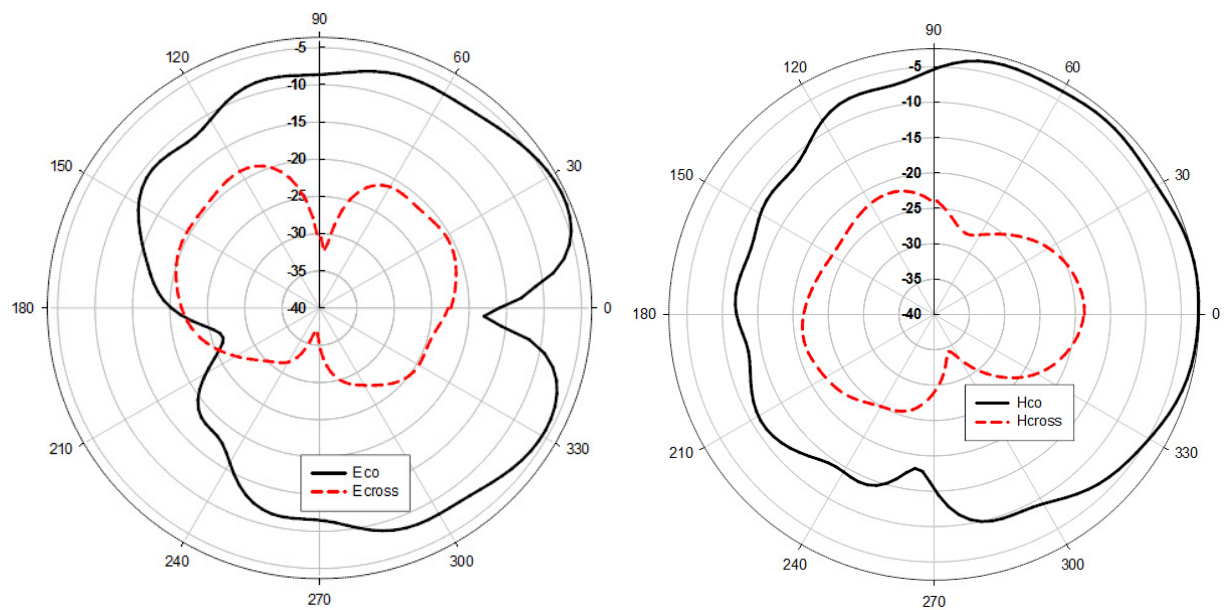

(b)

Figure. 7. Measured 2D radiation pattern of the antenna at E-plane and $\mathrm{H}$ - plane (a) At $3.5 \mathrm{GHz}$ (b) At $5.5 \mathrm{GHz}$

To study the excitation of the antenna, simulated surface current distributions at two resonant frequencies are shown in Fig. 8. From the figure it can be noticed that at lower resonant frequency of $3.5 \mathrm{GHz}$, the surface current density is more concentrated on the left side spur slot on the ground plane where for the $5.5 \mathrm{GHz}$ current is more perturbed across the right side spur slot. The open-ended tuning slit also plays an important role in bringing down the resonance to match with $50 \Omega$ characteristics impedance of the ACS feed line. 


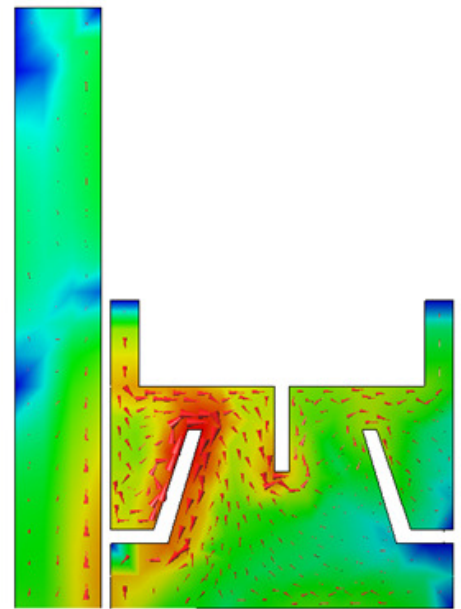

(a)

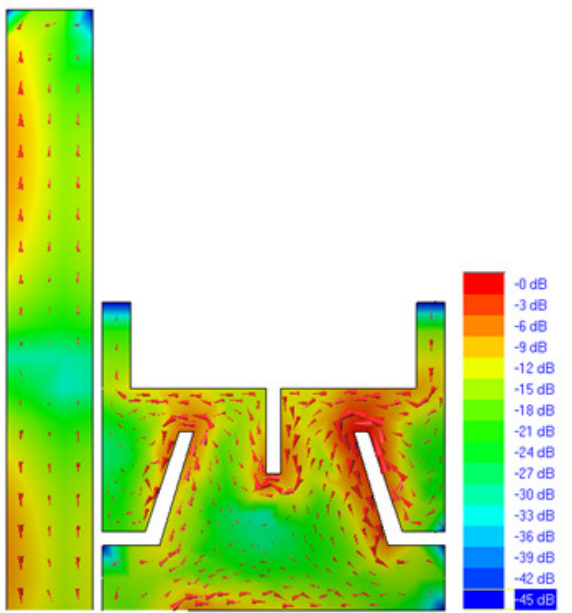

(b)

Figure.8 Simulated 3D surface current distribution of proposed antenna (a) At 3.5GHz (b) At 5.5GHz

The lumped equivalent model of the proposed design using RLC tank circuit which is connected in series is given in Fig.9. The circuit parameters are extracted and simulated by mentor graphics IE3D modua. The optimised values are obtained by after a large number of iterations and data fitting are $\mathrm{R}_{1}=47.3 \Omega, \mathrm{L}_{1}=0.31 \mathrm{nH}, \mathrm{C}_{1}=7.02 \mathrm{pF}$ and $\mathrm{R}_{2}=48.08 \Omega, \mathrm{L}_{2}=0.14 \mathrm{nH}, \mathrm{C}_{2}=5.36 \mathrm{pF}$.. The comparison of the reflection characteristics of the proposed structure with EM simulated and circuit simulated results are shown in figure .10. Here, it can be found that the results are showing good conformity between both.The circuit analysis is based on the flow chart is shown in figure.11

$$
\begin{aligned}
& R=2 Z_{0}\left(\frac{1}{\left|S_{11}\right|^{2}}-1\right) \Omega \\
& C=\frac{0.5 f_{c}}{\pi\left(f_{c}^{2}-f_{p}^{2}\right)} p F \\
& L=\frac{1}{4 \pi^{2} f_{0}^{2} C} n H
\end{aligned}
$$

The physical dimensions of the DGS affect the equivalent circuit parameters. The equivalent RLC circuit parameters of the DGS section should be extracted by the equations given above, where as the $f_{p}$ is the pole frequency and $f_{c}$ is the cut off frequency of approximated RLC circuit.

For finding the input impedance of the chosen center frequency, 


$$
Z_{\text {in }}=\frac{1}{\sqrt{\left(\frac{1}{R}\right)^{2}+\left(\frac{1}{\omega L}-\frac{1}{\omega C}\right)^{2}}}
$$

Using following relations [22] the values of the input impedance, the reflection coefficient, VSWR, return loss can be computed.

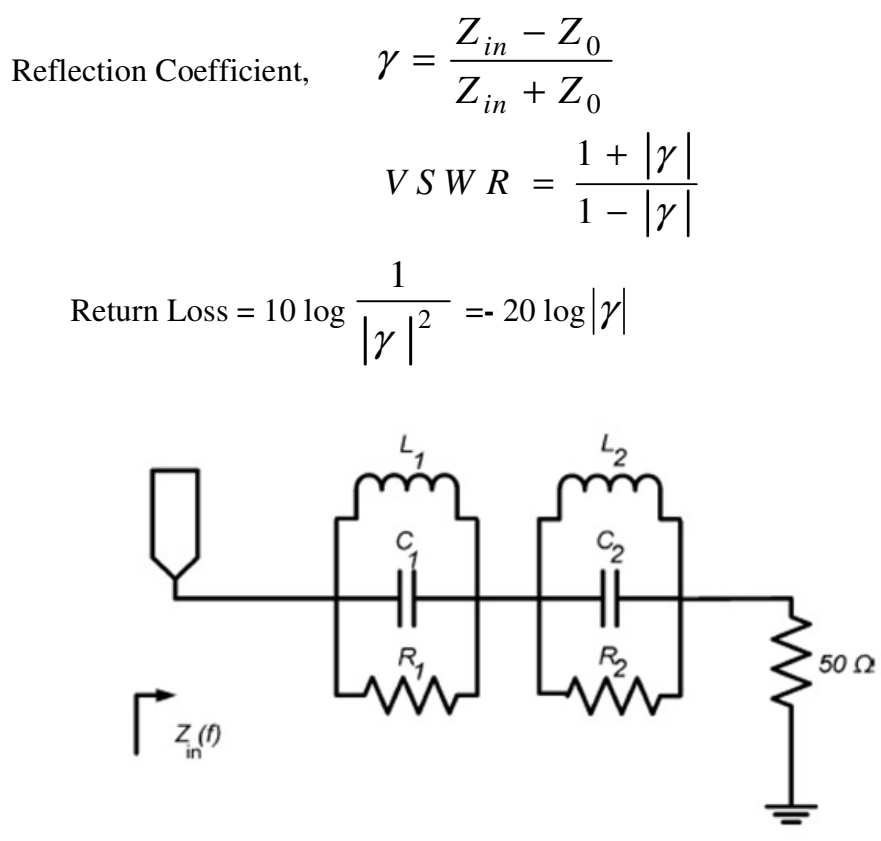

Fig. 9 Lumped equivalent model of the antenna

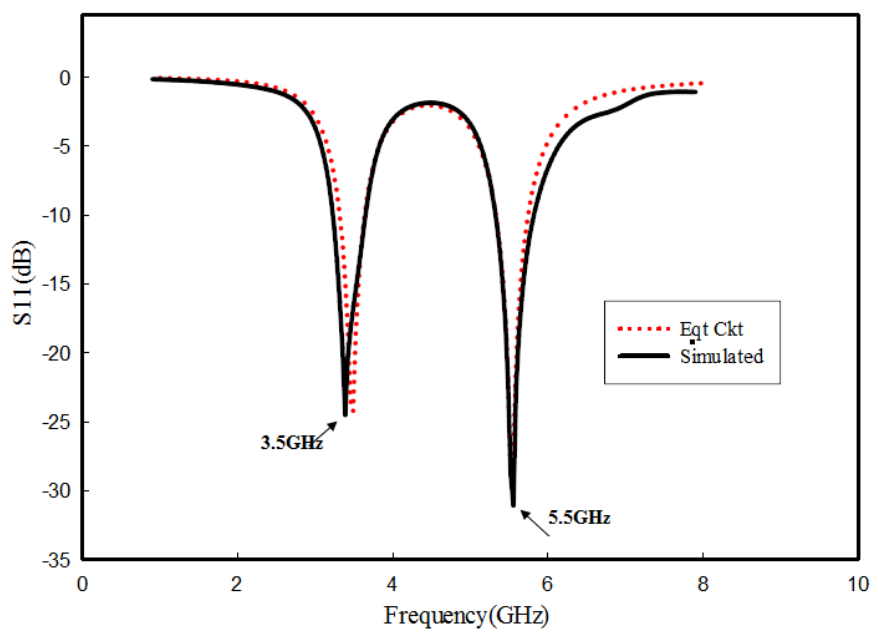

Figure. 10 Comparison between return loss characteristics circuit and EM simulation 
International Journal of Antennas (JANT) Vol.2, No.1, January 2016

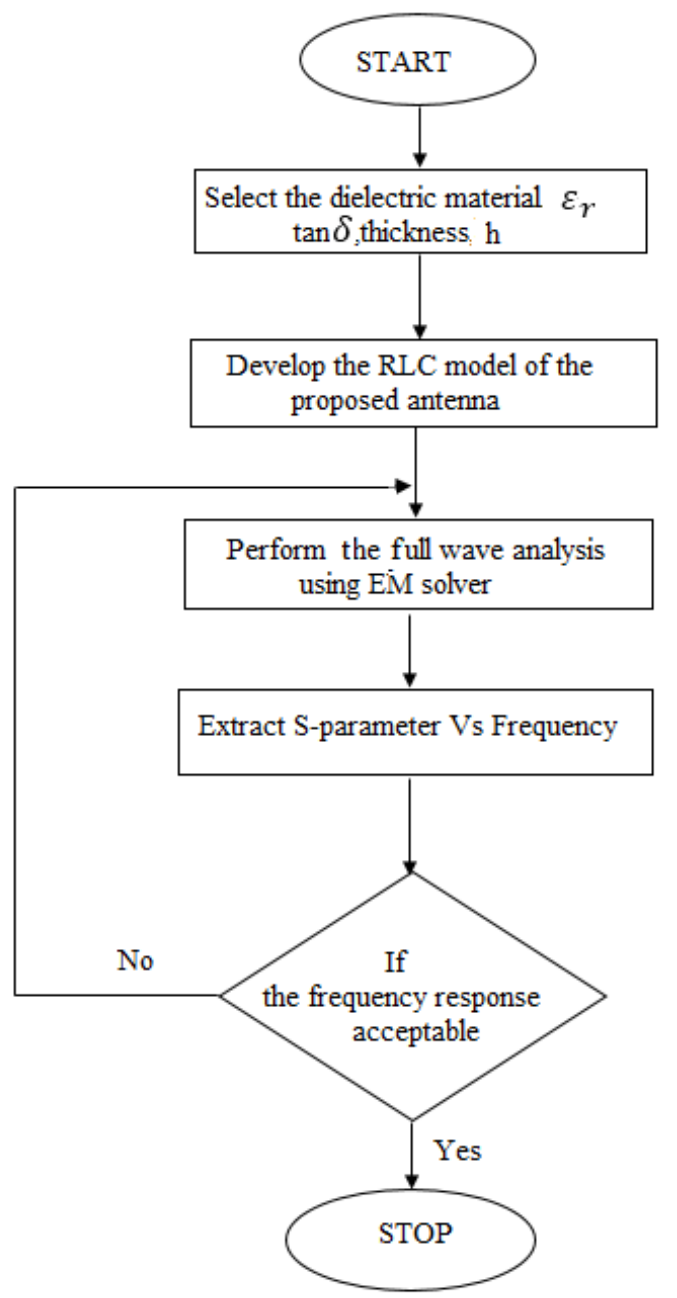

Figure. 11Flow chart for the equivalent circuit analysis

Table. 3 Comaparison of gain and area of antenna with existing literatures

\begin{tabular}{|c|c|c|c|}
\hline $\begin{array}{c}\text { Published } \\
\text { Literatures }\end{array}$ & $\begin{array}{c}\text { Antenna } \\
\text { purpose }\end{array}$ & Peak Gain(dBi) & Size(mm $\left.\mathbf{m}^{\mathbf{}}\right)$ \\
\hline proposed & WLAN/WiMAX & 3.9 & $21 \times 15$ \\
\hline$[7]$ & WLAN/WiMAX & 2.2 & $30 \times 28$ \\
\hline$[8]$ & WLAN/WiMAX & 1.9 & $21 \times 19$ \\
\hline$[10]$ & WLAN/WiMAX & 3.5 & $28 \times 12.5$ \\
\hline$[12]$ & WLAN/WiMAX & 1.21 & $37.5 \times 24$ \\
\hline$[13]$ & WLAN/WiMAX & 3.5 & $35 \times 19$ \\
\hline
\end{tabular}

The comparison between the overall size and gain of the antenna with already existing literatures are given in Table 3. Here, it can be found that the antenna has achieved a noticeable reduction in the area. The gain of the proposed structure is moderate as well as good. Fig. 12, shows the 
comparison between simulated and measured gain characterstics of the antenna. The average gain of proposed antenna is $2.5 \mathrm{dBi}$ in the first band of resonance and $3.9 \mathrm{dBi}$ in the second band of resonance, corresponding efficiencies about $76 \%$ and $82 \%$ respectively. So that the proposed structure isuseful for the present and future wireless portable gadgets

\subsection{General Format, Page Layout and Margins}

Standard A4 (210mm x 297mm) portrait page set-up should be used. The left, right, top and bottom margins should be $30 \mathrm{~mm}$. Do not use any headers, footers or footnotes. No page numbers. Single column. All main text paragraphs, including the abstract, must be fully (left and right) justified. All text, including title, authors, headings, captions and body, will be Times New Roman font.

\subsection{Title}

The title is to be written in 20 pt. Garamond font, centred and using the bold and "Small Caps" formats. There should be $24 \mathrm{pt}$. (paragraph) spacing after the last line.
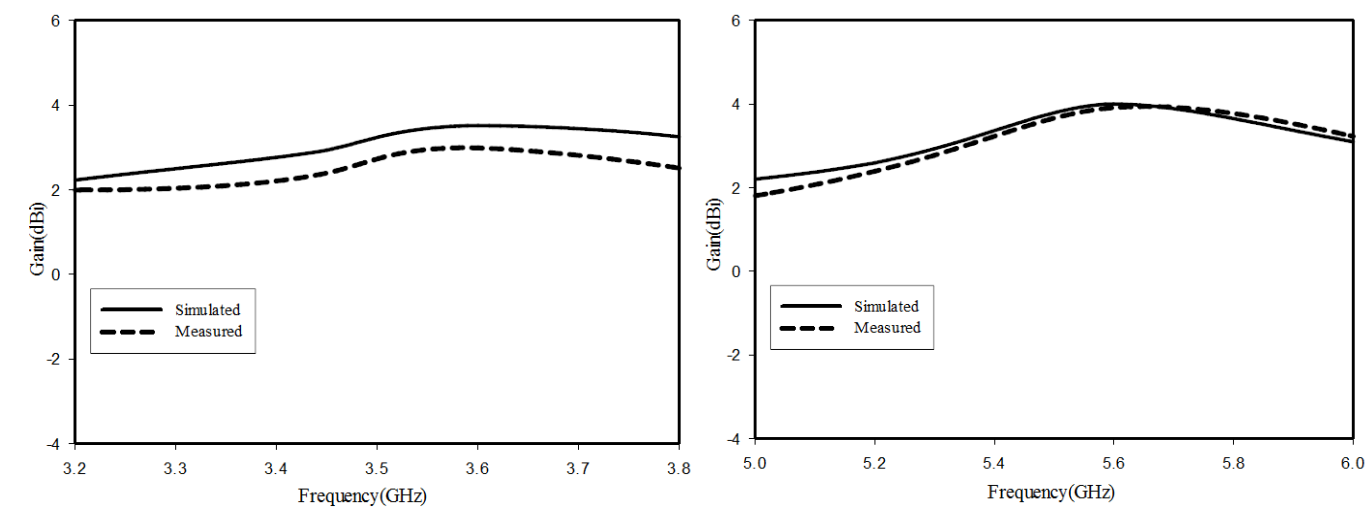

Figure.12 Comparison between measured and simulated gain characteristics in lower band of resonance and upper band of resonance

\section{CONCLUSiONS}

In this article main focus is given on the feed radiator as well as ground plane. The asymmetric coplanar strip planar feed is used here instead of coplanar waveguide and the use of ground plane modification with defected ground structure for further miniaturization. Here a novel compact ACS-fed dual band antenna with defected ground plane for WiMAX/WLAN application is proposed with a compact size of $21 \times 15 \times 1.6 \mathrm{~mm}^{3}$, designed, fabricated and measured. The simulated and measured results show that good conformity with standard results. The performance analysis of the antenna with different dielectric material properties also studied. The numerical simulation of approximate lumped equivalent model of the proposed structure shows good agreement with the simulated results. The measured results have demonstrated that the antenna can be achieved a desired band with enough bandwidth, good omnidirectional radiation characteristics and reasonable gain. As a result, the proposed antenna, with an advantage of compact size which is suitable for WiMAX/WLAN applications.

\section{ACKNOWLEDGEMENTS}


The authors are gratefully acknowledge to the University Grants Commission, New Delhi Government of India for their financial assistance and support.

\section{REFERENCES}

[1] Lai, C.-P., S.-C. Chiu, and S.-Y. Chen,Miniaturization of CPW-fed slot antennas using reactive terminations and truncated bilateral ground plane.IEEE Antennas Wireless Propag. Lett,Vol.11,pp.1072-1075,2012

[2] W.C. Liu, J.L. Jaw, and B.C. Chen,(2008) Triple-band CPW-fed monopole antenna with branch strips for wireless applications. Microwave Opt Technol Lett.;Vol. 50,pp.2794-2797,2008.

[3] Chow-Yen,Desmond Sim, "Dual band CPW fed monopole antenna with asymmetrical ground plane for bandwidth enhancement” Microwave Opt. Technol. Lett;Vol.50 pp.3001-3004,2008

[4] Sujith R, Deepu V, Mridula S, Paul B, Laila D, Mohanan P. Compact CPW-fed uniplanar antenna for multiband wireless applications. Int J Electron Commun, Vol.65, pp.553-9, 2011.

[5] Amendeep singh, surinder singh.A novel CPW-fed wideband printed monopole antenna with DGS.Int J Electron Commun Vol.69,pp.229-306,2015

[6] Yuanfu Liu, Peng Wang, Hao Qin. Compact CPW-fed tri-band stepped monopole antenna with inverted-L strip for WLAN/WiMAX applications; In Proc. of IEEE international conference on Electronic packaging technology ,pp.1244-1247,2014

[7] Deepu, V, R. Sujith, S. Mridula, C.-K. Aanandan, K. Vasudevan, and P. Mohanan, "ACS fed printed F-shaped uniplanar antenna for dual band WLAN applicationsMicrowave Opt. Technol.Lett,Vol.51,pp.1852-1856,2009

[8] V. Deepu, K.R. Rohith, J. Manoj, M.N. Suma, and P. Mohanan, Compact asymmetric coplanar strip fed monopole antenna for multiband applications, IEEE Trans Antennas Propag.,Vol.55 ,pp.2351-2357,2007

[9] Yuan Fu liu,Peng Wang,Hao Qin, A Compact triband ACS fed Monopole Antenna Employing Inverted L-branches for WiMAX and WLAN Application.Progress In Electromagnetics ResearchC;Vol. 47,pp.131-138,2014

[10] Yingsong Li,Wenxing $\mathrm{Li}$ and Qiubo $\mathrm{Yi}$ "Miniaturization of Asymmetric coplanar strip fed staircase ultra wide band antenna with reconfigurable notch band". Microwave Opt. Technol. Lett.Vol. 55,pp.1467-1470,2013

[11] Yingsong Li, Wenxing Li, Raj Mittra, "Miniaturization of ACS -fed dual band antenna with loaded capacitance termination",IEICE Electronic Express,Vol.10,pp.1-8,2013

[12] P. Askarali, S.Sreenath ,R Sujith,R.Dinesh,D.D Krishna, and C K Anandan, "Asymmetric coplanar strip fed dual Band Antenna for DCS/WLAN application”,Microwave Opt. Technol. Lett, Vol.54,pp.1087-1089,2012

[13] Li, B.; Yan, Z.; Zhang, T.: Triple band slot antenna with U shaped open stub fed by asymmetric coplanar strip for WLAN/WIMAX applications. Prog. Electromagn. Res. Lett.,Vol. 37: 123131,2013

[14] K A Ansal,T Shanmuganantham, Asymmetric coplanar strip fed antenna with defected ground structure for dual band application. In Proc. IEEE International Conference on Electronics and Communication Systems, ICECS'14,pp 359-362,2014

[15] Yue Song, Yong Chang Jiao "Compact slot antenna fed by asymmetric coplanar strip for 2.4/5 GHz WLAN operations”, Microwave and Opt. Technol. Lett..2008; 50:3080-3083.

[16] Thomas, K.-G. and Sreenivasan, M.: Compact triple band antenna for WLAN/WiMAX applications. Electron. Lett.Vol. 45,pp.811-813.2009

[17] Dang, L., Lei, Z.-Y. Xie, Y.-J., Ning, G.-L., and J. Fan, A compact micro strip slot triple-band antenna for WLAN/WiMAX applications. IEEE Antennas Wireless Propag. Lett. Vol.9,pp.1178$1181,2010$.

[18] Hu, W., Yin, Y.-Z; Fei, P. and Yang, X., "Compact tri band square-slot antenna with symmetrical L-strips for WLAN/WiMAX applications”, IEEE Antennas Wireless Propag. Lett. 2011; 10: 462465 .

[19] Weng, L. H., Guo, Y. C., Shi, X. W., and Chen. X. Q.: An overview of defected ground structure. Prog. Electromagn. Res, Vol.7:173-189,2008 
[20] K A Ansal, T Shanmuganantham, "ACS-Fed wide band antenna with L shaped ground plane for 5.5GHz WLAN application” Progress In Electromagnetics Res. Letter, Vol.49:59-64.2014 Simons, R.N.: “Coplanar Waveguide Circuits, Components and Systems”, John Wiley \& Sons,NY,2004

\section{Authors}

K. A Ansal received B.Tech Degree in Electronics and Communication Engineering from Mahatma Gandhi University,Kottayam, Kerala in 2007, M.E degree in communication systems from Anna University Chennai, India in 2011.He is currently Working towards Ph.D. degree at Department of Electronics Engineering, school of Engineering and Technology,Pondicherry university (Central university)puducherry, India .He has authored 15 journals and conference papers. Hisresearch interest include Microwave and millimeter wave antennas planar antennas with DGS and EBG and Mobile Base station antennas. He is a member of IEEE, IAENG and IEICE

T.Shanmuganantham received B.E. degree in Electronics and Communication Engineering from University of Madras, M.E. degree in Communication Systems from Madurai Kamaraj University and Ph.D. (Gold Medal) in the area of Antennas from National Institute of Technology, Tiruchirappalli, India under the guidance of Dr.S.Raghavan. He has 17 years of teaching experience in various reputed Engineering colleges such as SSN College of Engineering, National Institute of Technology and Science. Presently he is working as Assistant Professor in the Department of Electronics Engineering, School of Engineering \& Technology, Pondicherry University, and Pondicherry. His research interest includes Antennas, Microwave/MillimetreWaveIntegrated Circuits and Devices, EMI/EMC, Computational Electromagnetism, MEMS/NEMS Metamaterials. He has published 130 research papers in various national and International level Journals and Conferences. He is a member in IEEE, Life Member in IETE,Institution of Engineers, CSI, Society of EMC, OSI, ISSS, ILA, ISI, and ISTE.
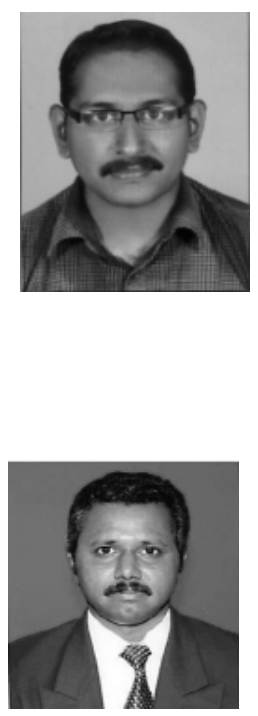